\title{
Thermosyphon-Assisted Cooling System \\ for Refrigeration Applications
}

\author{
Tao He, Chunlei Mei and Jon P. Longtin ${ }^{1}$ \\ Department of Mechanical Engineering, \\ State University of New York at Stony Brook, \\ Stony Brook, NY11794-2300, USA
}

\begin{abstract}
Residential refrigeration is one of the largest contributors to home appliance energy consumption in the U.S. This energy use is nearly doubled if commercial refrigeration is included. By using cold outside temperatures for cooling, however, energy savings can be realized. In this work, a thermosyphon-assisted cooling system for a household refrigerator is presented. A single finned copper-tube thermosyphon with methanol as the working fluid is used. An environmental chamber that can reproduce outside ambient temperatures to $-5^{\circ} \mathrm{C}$ is located above the refrigerator. Results are presented for different outside temperatures, fan speeds, and filling ratios in the thermosyphon. The electricity use for both the original equipment refrigeration and the thermosyphon system is reported. The interior temperature is found to vary depending on the number of fans that are used to blow air over the thermosyphon evaporator in the refrigerated space. This

\footnotetext{
${ }^{1}$ Corresponding author. Tel: 631 632-9436, Fax: 631 632-8544, Email: Jon.Longtin@ stonybrook.edu.
} 
can be used to produce localized micro-climates within the refrigerated space for further energy savings.

Keywords: thermosyphon; ambient cooling; residential refrigeration; commercial refrigeration; microclimate; appliance energy efficiency; appliance energy savings 


\section{Nomenclature}

$C_{p} \quad$ specific heat capacity, $\left[\mathrm{kg}^{-1} \mathrm{~K}^{-1}\right.$ ]

$h_{f g} \quad$ latent heat of vaporization $\left[\mathrm{J} \mathrm{kg}^{-1}\right]$

$k \quad$ thermal conductivity $\left[W \mathrm{~m}^{-1} \mathrm{~K}^{-1}\right]$

$L \quad$ length, $[m]$

$m$ mass of water used for thermal load, $[\mathrm{kg}]$

$P \quad$ electrical power, $[W]$

$Q \quad$ total heat transfer, $[J]$

$\dot{Q}_{r} \quad$ heat removal rate, [W]

$t \quad$ time, $[s]$

$T$ temperature, $\left[{ }^{\circ} \mathrm{C}\right]$

$T_{r} \quad$ refrigerator temperature, $\left[{ }^{\circ} \mathrm{C}\right]$

$T_{\infty} \quad$ ambient temperature, $\left[{ }^{\circ} \mathrm{C}\right]$

$W_{e} \quad$ electricity power, [W]

$W_{t h} \quad$ heat transfer rate, [W]

$\Delta T \quad$ temperature difference, $\left[{ }^{\circ} \mathrm{C}\right]$

Greek symbols

$\sum \quad$ mathematical symbol for summation

$\mu \quad$ dynamic viscosity [ $\left.\mathrm{N} \mathrm{s} \mathrm{m}^{-2}\right]$

$\rho \quad$ density $\left[\mathrm{kg} \mathrm{m}^{-3}\right]$

\section{Abbreviations}

COP coefficient of performance

$O E M$ original equipment manufacturers

\section{Subscripts}

a thermosyphon adiabatic section

c thermosyphon condenser section

cs climate simulator

$e \quad$ thermosyphon evaporator section

$l \quad$ liquid 


\section{INTRODUCTION}

U.S. households consumed more than $110 \times 10^{9} \mathrm{kWh}$ of delivered electricity for residential refrigerators in 2016 [1], representing $7 \%$ of the total electricity budget for the home. At a national average electrical cost of $\$ 0.12 / \mathrm{kWh}$, this represents an annual cost of $\$ 13 \mathrm{~B}$ and $84 \mathrm{M}$ metric tons of $\mathrm{CO}_{2}$ introduced into the atmosphere. Commercial refrigeration represents an additional $190 \times 10^{9} \mathrm{kWh} / \mathrm{yr}$ at a cost of $\$ 23 \mathrm{~B}$ and $145 \mathrm{M}$ metric tons of $\mathrm{CO}_{2}$ [2]. In nearly all refrigeration applications, the refrigerator resides in an environment maintained near $20-24{ }^{\circ} \mathrm{C}$, and uses electricity to move heat from the refrigerated space at a temperature of $2-5{ }^{\circ} \mathrm{C}$ to the environment. In many parts of the U.S., however, the outside temperature falls below the refrigerated space temperature for several months out of the year, particularly in the northern portions of the country. A natural choice then is to use the low outside temperatures during the cold season for cooling to reduce electricity usage for residential refrigerators.

One method to utilize low outside temperatures for near-zero-cost refrigeration is to place a two-phase thermosyphon inside of the refrigerated space, then to extend the top of the thermosyphon though the building envelope vertically or through a wall to the outside (Fig. 1). 


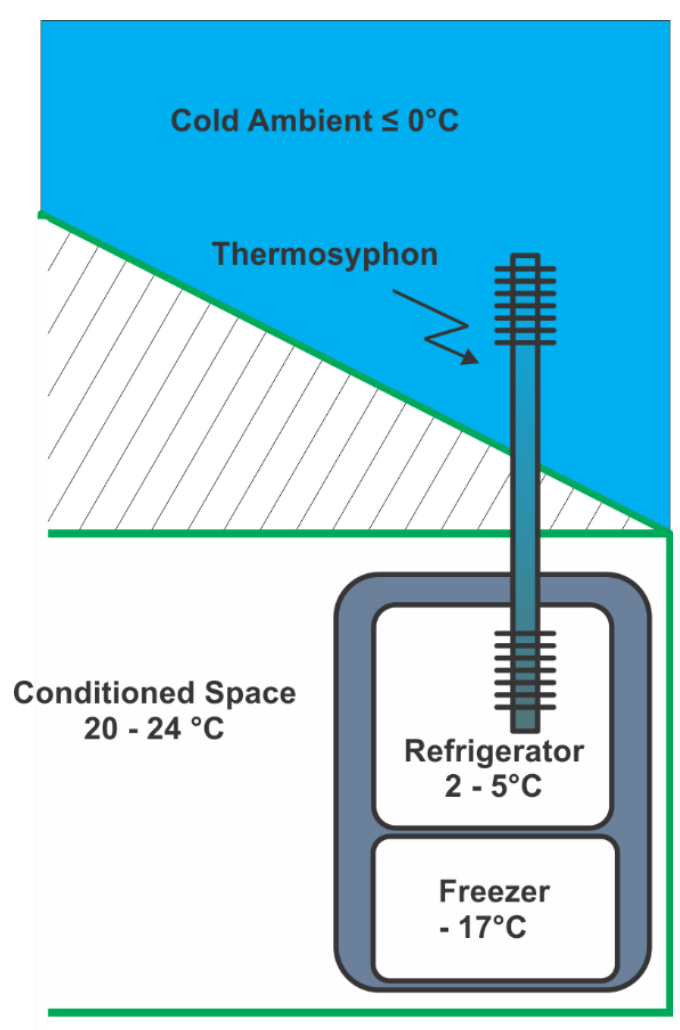

Fig. 1: Thermosyphon placed in a refrigerated space will remove heat when the ambient temperature is lower than refrigerated space.

The two-phase thermosyphon has several key features that make it well-suited for residential and commercial refrigeration applications. Because it uses the latent heat of phase change, the temperature difference required to move heat through the thermosyphon is very small. Thermosyphons are closely related to heat pipes, which are used extensively for cooling in electronic and computer equipment, high-performance heat exchangers, and satellites $[3,4]$. Unlike a heat pipe, however, heat flow only occurs if the temperature in the bottom section of the thermosyphon is greater than the temperature at the top because gravity maintains the liquid required for the phase change process in the bottom of the device only. In this sense, the device acts like a thermal diode or check valve, and will automatically shut-off when the ambient temperature exceeds the refrigerated space temperature. 
The thermosyphon operation is completely passive, with no pump needed since phase change and gravity alone drive the heat transfer process. There are no moving parts and the device is permanently sealed at the time of manufacture. The device is inexpensive and can be made using a variety of materials and working fluids best suited for the application.

The low thermal resistance provided by the thermosyphon is important so that it can provide the required cooling with as warm an ambient temperature as possible. The relationship between heat flow, temperature difference, and thermal resistance through the thermosyphon is

$$
\dot{Q}_{r}=\left(T_{r}-T_{\infty}\right) / R_{t h}
$$

Here $\dot{Q}_{r}$ represents the steady-state heat removal rate required to maintain the refrigerated space at the desired temperature, $T_{r}$. The ambient temperature is $T_{\infty}$ and $\Delta T=T_{r}-T_{\infty}$ is the temperature difference between the refrigerated space and the ambient temperature. For a residential refrigerator, the average $\dot{Q}_{r}$ is $\sim 40-50 \mathrm{~W}$ [5], and varies with the size of the refrigerator, the temperature set point $\left(T_{r}\right)$, effectiveness of the insulation, volume of food added/removed, and the number and duration of door-opening events. Typical ranges for $T_{r}$ are $2.8-4.5^{\circ} \mathrm{C}\left(37-40{ }^{\circ} \mathrm{F}\right)$. The total thermal resistance, $R_{t h}$, includes all thermal resistances in moving the heat from the air in the refrigerated space to the ambient air. Since $\dot{Q}_{r}$ and $T_{r}$ are fixed, $R_{t h}$ will dictate the maximum ambient temperature, $T_{\infty}$, that will provide the required cooling with the thermosyphon. Minimizing $R_{t h}$ will thus maximize the hours per year that the system will provide cooling. If the thermosyphon system cannot provide $100 \%$ of the required cooling, the refrigerator will simply cycle its own vapor-cycle-based refrigeration system so that the refrigerator contents are not compromised. 
Thermosyphons have been used in a variety of engineering applications, including air-air heat exchangers $[6,7]$, protection of permafrost degeneration [8], and solar heating systems [9, 10]. However, there is little research into the application of thermosyphons for refrigeration applications by using cold outdoor temperatures. The SunFrost commercial refrigerator system [11] was developed in the early 1980s. Although the product literature referred to a heat pipe as the key heat transfer device, it actually appeared to be a two-phase thermosyphon that was used. The refrigerator did not achieve significant commercial success and the product was abandoned after several years. A more recent study used a SunFrost unit as well as two additional traditional refrigerators modified to include thermosyphons [12]. The thermosyphons in their systems did not have fins or fans in the cabinet to enhance heat transfer. They also required a temperature difference of $\sim 21^{\circ} \mathrm{C}$ between the refrigeration compartment and ambient temperature in order to operate, which significantly limits the hours per year and the locations in which such a system will work.

In this study, a commercial, freezer-less residential refrigerator was retrofitted by installing a thermosyphon and tangential fans on both the evaporator and condenser section of the thermosyphon. A climate simulator chamber was built to simulate a range of outdoor cold temperature conditions. The impact of the ambient outside temperature, the temperature distribution inside the refrigerator, the dynamic cooling performance, and the system's energy consumption are measured and discussed. 


\section{THERMOSYPHON PRINCIPLES AND OPERATION}

\subsection{Principle of Operation}

A two-phase closed thermosyphon is a type of heat pipe without an internal wick [13], as shown in Fig. 2. It is simple in construction and design, consisting of a hollow tube that is oriented vertically and has been evacuated and filled with a working fluid. Heat is added at the bottom of the device in the evaporator, vaporizing the working fluid and causing it to rise to the top of the device to the condenser. Heat is removed in the condenser, causing the vapor to condense onto the pipe wall. The liquid flows back down the sides to the evaporator by gravity and the process repeats. An optional, insulated middle section, called the adiabatic section, may be present as well.

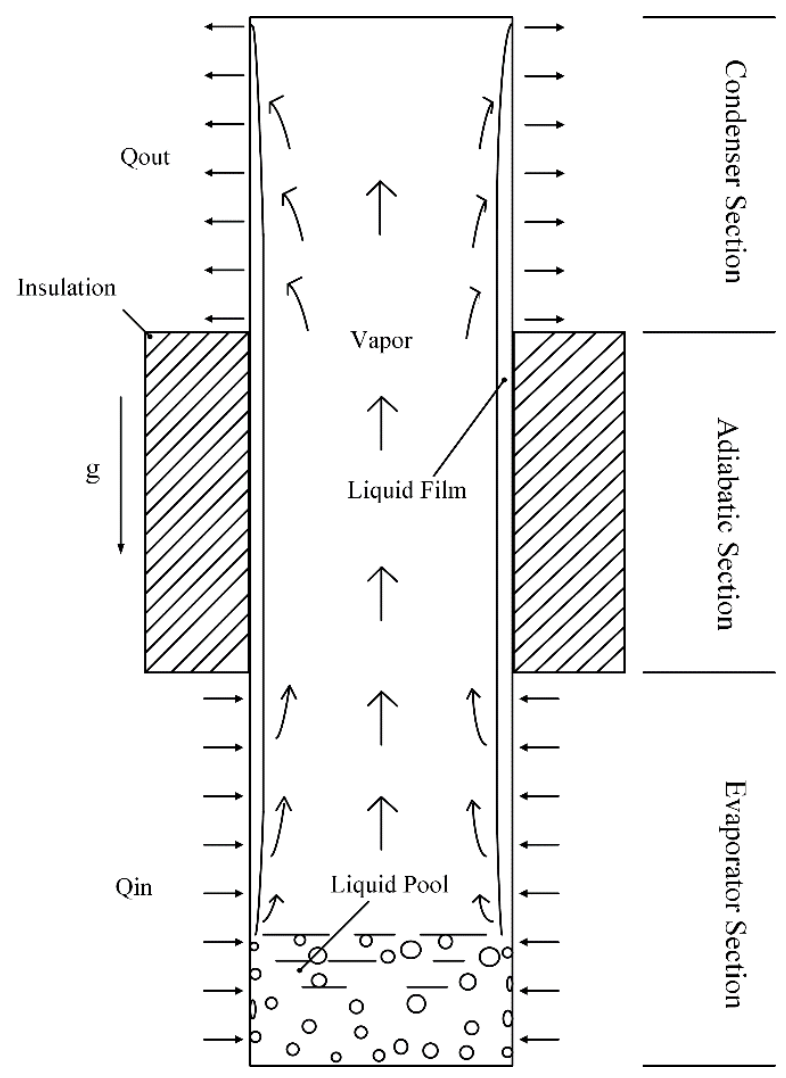

Fig. 2: Schematic of the two-phase closed thermosyphon 
The heat transfer mechanisms in the evaporator are more complicated than those in the condenser because the falling liquid film and the liquid pool in the bottom of the device participate in the phase change and heat transfer simultaneously. Different heat transfer regimes are possible, depending on the intensity of the wall heat flux in both liquid film and liquid pool [14, 15].

Several factors limit to the maximum heat transfer that can pass through the thermosyphon. Dry-out occurs $[16,17]$ when there is not enough working fluid present, and dry regions form on the evaporator walls. Conversely, if too much liquid is present, pool flooding occurs, in which the liquid pool fills and then expands beyond the evaporator section due to nucleate boiling. The counter-current flooding limit [18] occurs at high vapor velocities where the upwardmoving vapor exerts significant shear stress on the falling liquid film, causing the film thickness to increase or separate from the wall completely.

\subsection{Thermosyphon Model}

A simulation model was developed to predict the operating parameters of the thermosyphon based on its geometry, working fluid, and thermal boundary conditions. The model allows varying these parameters to minimize the thermal resistance, as discussed above. Thermosyphons have been studied extensively in the literature. The model developed by Jiao et al. [19] was adapted for used in this work. The model solves the 1-D conservation of energy mass and momentum equations in the evaporator, condenser, and adiabatic section of the thermosyphon. The liquid film thickness and temperature drop across the thermosyphon as a function of heat input are provided from the model. The falling film and liquid pool in the evaporator are treated independently, with the various boiling regimes incorporated through empirical relationships in both the film and the pool. The model also identifies the operating limits of the thermosyphon, includ- 
ing the flooding, dry out and sonic limits. The resulting model is represented by a set of coupled ordinary differential equations that are solved using the MATLAB ${ }^{\circledR}$ programming language.

In the simulation, the condenser is treated as a convective boundary condition and the evaporator as a constant-heat-flux boundary condition. Strictly speaking, the actual refrigerator application has convective boundary conditions at both the evaporator and condenser. The reasons for using the constant heat-flux boundary condition are that (1) nearly all prior modeling has adopted this boundary condition, largely because the expressions for boiling used to determine the heat transfer in the liquid pool are all based on a heat-flux boundary condition, and (2) the thermosyphon represents only a small portion of the overall thermal resistance in moving the heat from the refrigerated space to the ambient; rather the heat transfer to and from the fins on the evaporator and condenser, respectively, dominate the thermal resistance. As such, the error introduced with a constant-heat flux boundary condition is small when the overall heat transfer is considered while still allowing the use of well-established models to be used to predict the thermosyphon operation.

Several candidate working fluids were investigated, including methanol, ethanol, R134A, water, and ammonia. First, the figure of merit FOM, which characterizes a fluid's expected performance for the thermosyphon based on its thermal properties, is calculated as follows [20]:

$$
F O M=\left[\frac{h_{f g} \rho_{l}^{2} k_{l}^{3}}{\mu_{l}}\right]^{0.25} .
$$

Here $h_{f g}$ is the latent heat, $\rho_{l}$ the density, $k_{l}$ the thermal conductivity, and $\mu_{l}$ the liquid viscosity. Larger values of the FOM are better. The FOM for each working fluid is shown in Table 1.

The 1-D model was also run for each working fluid. Filling ratios of 5\% and 10\% and heat inputs of $40 \mathrm{~W}$ and $60 \mathrm{~W}$ were considered. The vapor temperature inside the thermosyphon 
was taken to be $0{ }^{\circ} \mathrm{C}$, as this represents a typical vapor temperature for a thermosyphon operating between a $3{ }^{\circ} \mathrm{C}$ refrigerated space and an ambient outside temperature several degrees cooler. The exception was for water, in which a $5{ }^{\circ} \mathrm{C}$ vapor temperature was used was used to avoid freezing in the condenser. The temperature difference between the evaporator and condenser is reported for each fluid, filling ratio and heat input in Table 1. Lower values of the temperature difference are better.

Table 1: Working fluid FOM and temperature difference from simulation

\begin{tabular}{|c|c|c|c|c|c|}
\multirow{2}{*}{ Working Fluid } & \multirow{2}{*}{ FOM } & \multicolumn{4}{|c|}{ Evaporator-Condenser Temperature Difference $\left({ }^{\circ} \mathrm{C}\right)$, } \\
\cline { 3 - 6 } & & \multicolumn{2}{|c|}{$Q=40 \mathrm{~W}$} & \multicolumn{2}{|c|}{$Q=60 \mathrm{~W}$} \\
\cline { 3 - 6 } & & $\mathrm{FR}=5 \%$ & $\mathrm{FR}=10 \%$ & $\mathrm{FR}=5 \%$ & $\mathrm{FR}=10 \%$ \\
\hline Ammonia & 4,796 & $0.12^{\circ} \mathrm{C}$ & $0.11^{\circ} \mathrm{C}$ & $0.2{ }^{\circ} \mathrm{C}$ & $0.24^{\circ} \mathrm{C}$ \\
\hline Water & 4,177 & $0.31^{\circ} \mathrm{C}$ & $0.53^{\circ} \mathrm{C}$ & $0.49^{\circ} \mathrm{C}$ & $0.81^{\circ} \mathrm{C}$ \\
\hline Methanol & 1,732 & $0.47^{\circ} \mathrm{C}$ & $0.52{ }^{\circ} \mathrm{C}$ & $0.81^{\circ} \mathrm{C}$ & $0.89{ }^{\circ} \mathrm{C}$ \\
\hline R134a & 993 & $0.74^{\circ} \mathrm{C}$ & $0.68{ }^{\circ} \mathrm{C}$ & $1.03^{\circ} \mathrm{C}$ & $1.08{ }^{\circ} \mathrm{C}$ \\
\hline Ethanol & 1,142 & $0.77^{\circ} \mathrm{C}$ & $0.88^{\circ} \mathrm{C}$ & $1.28^{\circ} \mathrm{C}$ & $1.52^{\circ} \mathrm{C}$ \\
\hline
\end{tabular}

Based on the FOM and model results, methanol is chosen as the working fluid for this application, as it provides good overall performance for the temperature range needed for the refrigeration application. Water is ruled out because it will freeze at outdoor temperatures below $0{ }^{\circ} \mathrm{C}$ and its falling liquid film tends to break up into rivulets due to its high surface tension and 
high latent heat in this application [20]. Ammonia is an excellent working fluid but is ruled out due to its significant health and handling risks, and its strong reactivity with copper.

\section{MATERIALS AND METHODS}

\subsection{Thermosyphon Fabrication}

A custom copper tube with annular-fins (Fin Tube Products, Inc.) was acquired to serve as the thermosyphon for this work. The dimensions of the thermosyphon pipe are shown in Table 1.

Table 2: Thermosyphon Geometry

\begin{tabular}{|cc|}
\hline Geometric Parameter & Value \\
\hline Total Length: $L(\mathrm{~cm})$ & 227 \\
\hline Evaporator Length: $L_{e}(\mathrm{~cm})$ & 102 \\
\hline Adiabatic Length: $L_{a}(\mathrm{~cm})$ & 23 \\
\hline Condenser Length: $L_{c}(\mathrm{~cm})$ & 102 \\
\hline Inner tube diameter $(\mathrm{mm})$ & 17 \\
\hline Wall thickness $(\mathrm{mm})$ & 1.2 \\
\hline Fin height $(\mathrm{mm})$ & 9.5 \\
\hline Fin thickness $(\mathrm{mm})$ & 0.4 \\
\hline Fin spacing $(\mathrm{mm})$ & 1.6 \\
\hline
\end{tabular}

The evaporator section is located within the refrigerated space, and the condenser section is placed within a cold-climate simulator. The adiabatic section resides between the evaporator and the condenser. It has no fins and is surrounded with $2.5 \mathrm{~cm}$ pipe insulation to minimize heat loss. The top of the thermosyphon assembly is fitted with a series of ball valves for evacuation, fluid filling, and pressure monitoring.

To add the methanol, a vacuum pump and valve system arrangement were used to evacuate the thermosyphon to a pressure of $\sim 0.01 \mathrm{mmHg}$, followed by the addition of the desired volume of methanol. In this work filling ratios, defined as the ratio of working fluid volume to 
the evaporator section volume, of 5\% and $10 \%$ were used, and were obtained by filling with 15.6 $\mathrm{mL}$ and $31.3 \mathrm{~mL}$ of methanol, respectively. A low filling ratio is desirable, as the thermal resistance of the pool is generally higher than the resistance through the falling liquid film in the evaporator (Fig. 2) [21]. The methanol volume was measured and introduced using a $30 \mathrm{~cm}^{3}$ syringe and short length of vinyl tubing to avoid introducing air into the evacuated thermosyphon during the filling procedure.

To remove any residual non-condensable gas in the thermosyphon, a degassing procedure was conducted before the test began. The evaporator section was heated with a heat gun and the condenser section was cooled by the climate simulator to drive the non-condensable gas towards the top (condenser) region where the filling values are located. The vacuum pump was then turned on and the vacuum valve opened for 3-5 seconds to remove the non-condensable gas. This procedure was repeated several times. To make up for the possible loss of methanol working fluids during the degas process, an additional $2-3 \mathrm{~mL}$ of methanol was added during the charging process mentioned above.

\subsection{Experimental Configuration}

A schematic and image of the experimental setup are shown in Figure 3. A commercially available residential refrigerator (Frigidaire FRU17B2J) is used for the testing. The unit is a refrigerator only, with no freezer section. Cooling is maintained by cycling the OEM refrigeration system on or off; there is no ability to modulate the delivered cooling. The refrigerator also incorporates a defrost cycle that runs for 30 minutes after every 12 hours of compressor cumulative running time. During the defrost cycle, the refrigeration unit pauses and a defrost heater is switched on, with a measured electrical power rating of $453 \mathrm{~W}$. 
The climate simulator chamber is located directly above the refrigerator. The enclosure is fabricated from 50-mm thick rigid polystyrene insulation (Owens Corning). A Neslab RTE140 chiller provides chilled water to a Koolance liquid-air heat exchanger plate inside the climate simulator. Six 12 VDC $120 \mathrm{~mm}$-diameter fans provide airflow over the heat exchanger. The air within the simulator was dried using $0.9 \mathrm{~kg}$ of silica gel in a porous container to avoid ice forming on the heat exchanger.
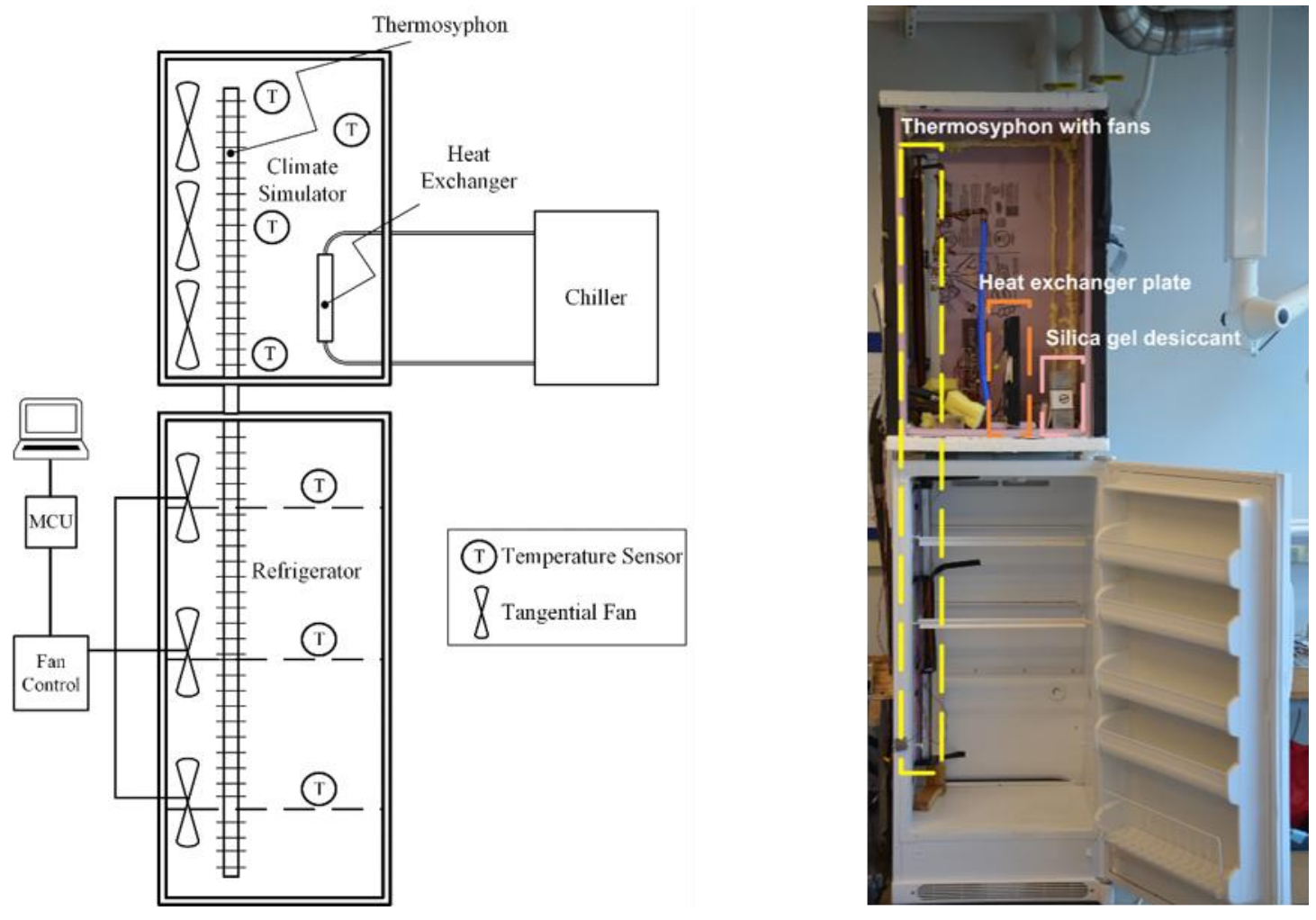

Fig. 3: Experimental schematic of the thermosyphon-assisted cooling system (Left), overall setup for the thermosyphon-assisted cooling system (temperature sensors not shown, right)

Six $41.3 \mathrm{~cm}$-length long high-efficiency 24-VDC tangential fans (Ebmpapst) are used to force air over the thermosyphon evaporator and condenser. Three fans are located in the refrigerated section, and the remaining three are located in the climate simulator. The fans are placed $2-3 \mathrm{~cm}$ from the thermosyphon, and aluminum sheet is used to duct the airflow through the thermosy- 
phon fins. The fans can be individually turned on or off, and their speed modulated by using pulse-width-modulation from a microcontroller.

Temperature measurements in the refrigerator and the climate simulator were made using DS18B20 digital temperature sensors (Dallas Semiconductor), which have a stated accuracy of $\pm 0.5^{\circ} \mathrm{C}$. These sensors were located in the refrigerator space at the center of the top, middle, and bottom shelves. Four additional sensors were located in the top, middle and bottom portions of the climate simulator. The ambient temperature of the room in which the refrigerator operates was monitored using an Oregon THGR268 sensor, which has a stated accuracy of $\pm 1.0^{\circ} \mathrm{C}$. An Arduino Uno microcontroller was used for data acquisition and control.

Two Keithley 2000 digital multimeters were employed to measure the current and voltage of the fans to determine their electrical power consumption. To measure the power consumption of the refrigerator's own cooling system, a Watts Up? PRO AC meter was used. To provide an accurate average of the power usage, data was collected for $23 \mathrm{~h}$.

When testing the thermosyphon cooling system, the refrigerator was unplugged to eliminate any cooling contribution from the refrigerator's own cooling system. All fans were turned on, and the chiller temperature was then adjusted to obtain the target temperature in the climate simulator. The system was maintained in this condition until the refrigerator, the climate simulator, and ambient room temperatures stabilized (typically 2-4 h). The refrigerator door remained closed at all times during the test.

\section{RESULTS AND DISCUSSION}

A series of tests were performed in order to investigate the performance of the thermosyphonassisted cooling refrigerator system. 


\subsection{Original Refrigerator COP}

The cooling performance of the refrigerator's original equipment manufacturer (OEM) cooling system was determined to provide a comparison to the thermosyphon-assisted cooling system. The overall coefficient of performance $(C O P)$ is defined as follows:

$$
C O P \equiv \frac{\dot{Q}_{c}}{P_{r e}}
$$

Here $\dot{Q}_{c}$ is the heat removed from the interior of the refrigerator and discharged to the room surroundings, and $P_{r e}$ is the electrical power consumed by the refrigerator compressor and fans. The interior light was disabled to avoid its contribution to the electrical and thermal loads. The heat flow is determined as follows. When the refrigerator is in steady state, and in the absence of door-open events, the cooling system removes the heat that migrates into the refrigerator interior, $\dot{Q}_{c 0}$. To determine $\dot{Q}_{c 0}$, a series of additional heat inputs $\dot{Q}_{i n}$ was added to the refrigerator and the increase in the refrigerator electricity consumption was recorded. The relationship between $P_{r e}$ and $\dot{Q}_{\text {in }}$ thus becomes

$$
P_{r e}=\frac{1}{C O P}\left(\dot{Q}_{c 0}+\dot{Q}_{i n}\right)
$$

The heat load was provided with two $100 \mathrm{~W}$ incandescent light bulbs placed at the bottom of the refrigerated space. The bulbs were covered with aluminum foil to minimize radiation heat transfer to the temperature sensors. Electrical power to the bulbs was adjusted using a variable AC transformer (Variac), while the voltage and current were measured after the transformer using two Keithley 2000 multimeters. The bulb power was varied from 0 to $120 \mathrm{~W}$ in $20 \mathrm{~W}$ increments. The number of refrigerator defrost cycles was one or two, depending on the heat load, 
with higher heat loads yielding an extra defrost cycle due to the increased compressor run time. The refrigerator interior temperature was maintained at $3.5^{\circ} \mathrm{C} \pm 0.6^{\circ} \mathrm{C}$ using the $\mathrm{OEM}$ cooling system and ambient room temperature was $21.9^{\circ} \mathrm{C} \pm 1.1^{\circ} \mathrm{C}$ during the tests.

The results are shown in Fig. 4, plotted as the bulb heat power versus OEM refrigerator electrical power consumption. As can be seen, the power consumption is nearly linear with the heat load. The slope of the line is $0.68\left(\mathrm{~W}_{\mathrm{e}} / \mathrm{W}_{\mathrm{th}}\right)$. The reciprocal of this value, $1.47\left(\mathrm{~W}_{\mathrm{th}} / \mathrm{W}_{\mathrm{e}}\right)$ is the overall COP of the refrigerator from Eq. (4). The estimated electricity use with no lamp load is $28.7 \mathrm{~W} \pm 0.3 \mathrm{~W}$, which corresponds to the normal heat leakage into the refrigerated section in the absence of any internal heat load. From the slope of the regression line in Fig. 4, the heat load $Q_{c 0}$ is estimated to be $42.2 \pm 0.7 \mathrm{~W}$.

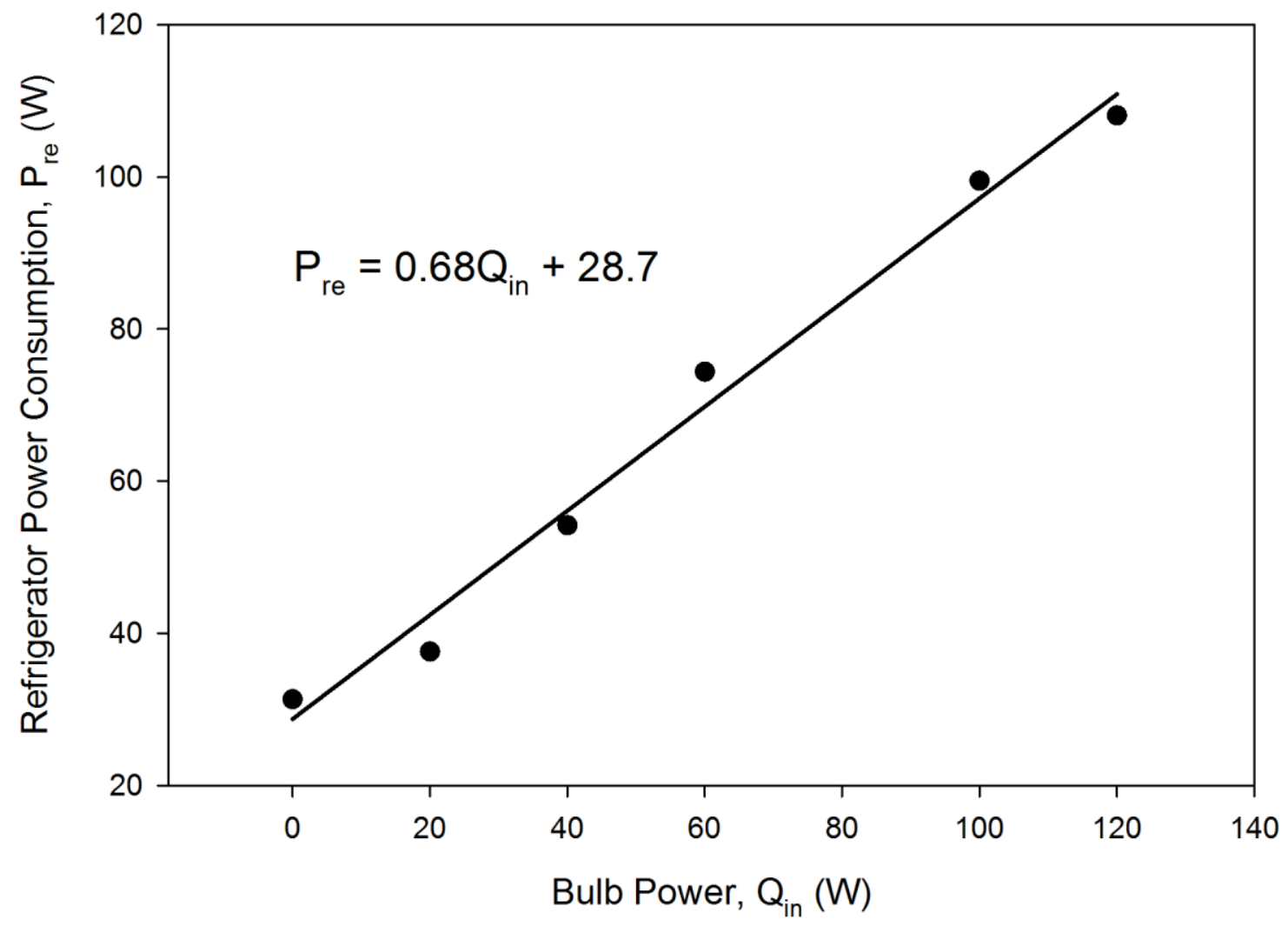




\section{Fig. 4: Refrigerator's own cooling system's energy consumption vs heating elements' (bulbs) power}

\subsection{Steady State Operation of Thermosyphon-Assisted Cooling System}

The first series of tests with the thermosyphon cooling system were done for steady-state operation of the refrigerator in which the door remains closed, and all items within the refrigerator are in thermal equilibrium with the refrigerated space. The only heat loads in this case are: (1) the heat leakage into the refrigerator, which is largely independent of the food load, and (2) any heat provided by the defrost cycle. There are two goals: (1) minimize the temperature between the outside ambient temperature and the refrigerated space, and (2) provide this minimal temperature with as little electricity use for the fans as possible.

The following parameters were varied for this test: (1) temperature of climate simulator, (2) number of fans in operation in the refrigerated compartment, and (3) filling ratio of the thermosyphon. All three fans in the climate simulator were run for all tests. The climate simulator temperatures ranged from $-5.1{ }^{\circ} \mathrm{C}$ to $-0.6^{\circ} \mathrm{C}$. The lower value represents the coldest temperature that the chiller was able to produce in the climate simulator, while the upper limit was selected to ensure that the refrigerator interior temperature would not exceed the maximum FDArecommended temperature of $4.5^{\circ} \mathrm{C}\left(40^{\circ} \mathrm{F}\right)$ to avoid spoilage of perishable items [22].

The thermosyphon fans in the refrigerator space were turned on in the following combinations: (i) all fans on, (ii) all fans off, (iii) top and bottom fans on, (iv) top fan only, (v) middle fan only, and (vi) bottom fan only. When turned on, the fans ran at full speed. These combinations were chosen to assess the thermal performances vs. additional electricity cost for the fans. Also, there is a thermal penalty for using more fan power because the electricity provided to the fans represents an additional heat load that must be removed from the refrigerated space. Ther- 
mosyphon fill ratios of $5 \%$ and $10 \%$ were tested to determine if a significant performance difference was observed.

Temperatures were reported separately for the bottom, middle, and top shelves in the refrigerated space. This is necessary to both assess temperature stratification as well as account for situations when different combinations of fans are turned on or off. Each test was run for at least 12 hours after the system reached steady state.

The results are shown in Fig. 5 and Fig. 6. A 5\% filling ratio is used in all cases, except in 7(d), in which $10 \%$ filling ratio is used. In Fig. 5a, all three fans are on, which represents the maximum cooling capability, at the expense of the most electricity used, and the largest heat addition to the refrigerated space. Temperatures at the top, middle, and bottom shelves are presented for several climate-simulator temperatures. The temperature difference between the refrigerator and climate simulator remained nearly constant at $5.0-5.5^{\circ} \mathrm{C}$, regardless of the climate simulator temperatures or shelf position. The bottom shelf was about $1{ }^{\circ} \mathrm{C}$ warmer than the middle and top shelves, which is likely due to the liquid pool located at the bottom of the thermosyphon, which has a higher thermal resistance than the evaporating film on the walls above the pool (Fig. 2) [21].

In Fig. 5b, the bottom fan is shut off. The distribution of top shelf temperature and bottom shelf temperature is nearly the same as for all fans on. However, the middle shelf temperature has increased by more than $0.5^{\circ} \mathrm{C}$ relative to the top shelf, even though its fan remains on. The increase may be due to heat flow from the bottom shelf via natural convection.

The temperature data for top, middle, and bottom fans operating individually is shown in Fig. 6a-c, respectively. As expected, the shelf next to the fan that is on has a lower temperature compared to the other two shelves. However, the overall temperature in the space varied consi- 
derably depending on which fan is on. For the case of the top fan on only, the middle and bottom shelf temperatures are still marginally in the acceptable range of $4.5^{\circ} \mathrm{C}$ or less. For the middle or bottom shelf fans on, however, the temperatures in the refrigerated space are considerably higher, and would be unacceptable in most conditions. Explanations for this variation include the poorer performance of the liquid pool at the bottom of the thermosyphon mentioned above. Buoyancy effects may also be coming into play, as air cooled near the upper region of the refrigerated space will sink to the bottom, whereas cooler air already at the bottom will tend to remain there.

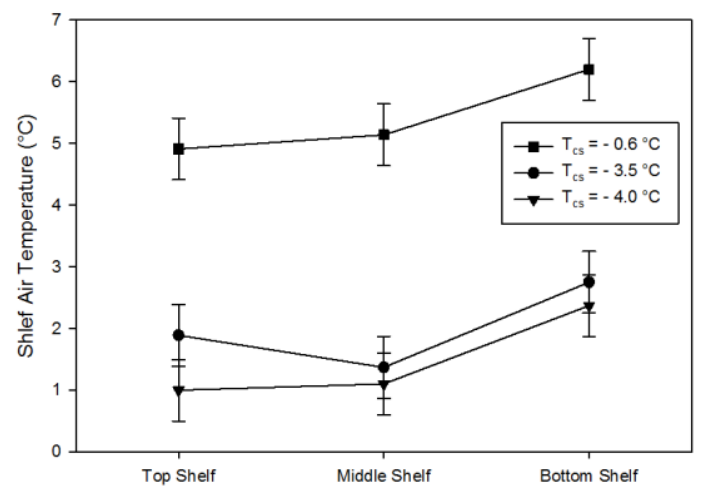

(a)

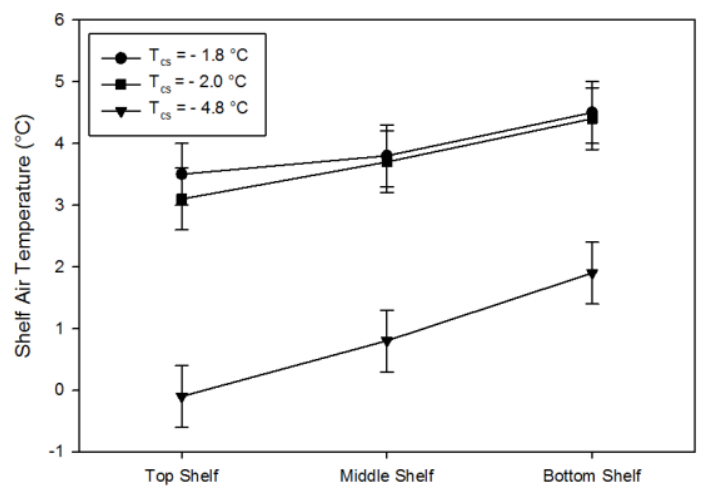

(b)

\section{Fig. 5: Temperature distribution inside the cabinet at $5 \%$ thermosyphon filling ratio. (a) all three fans in refrigerated section are on, (b) top and middle fans on, bottom fan off}

Shelf temperatures for a filling ratio of $10 \%$ are shown in Fig. 6d. There is no distinct difference from those for a $5 \%$ filling ratio. As such, a low filling ratio works well for this application and an exact filling ratio does not appear to be necessary. Care should be taken, however, to ensure that none of the traditional thermosyphon limits are exceeded for normal refrigeration operation. 
The case for all fans off in both the refrigerated space and the climate simulator yielded a large temperature difference between the two spaces. When the climate simulator temperature was $-2^{\circ} \mathrm{C}$, the refrigerated space rose to nearly $20^{\circ} \mathrm{C}$. This suggests that very cold outside conditions can be accommodated by simply shutting all fans off to prevent freezing the food in the refrigerator.

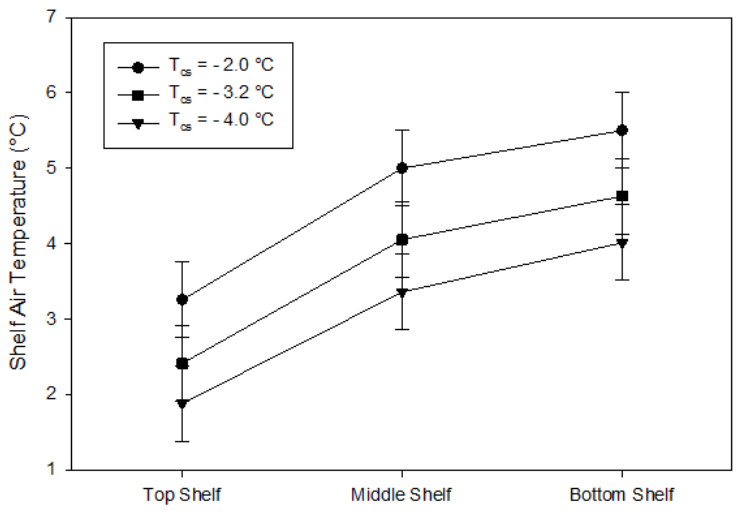

(a)

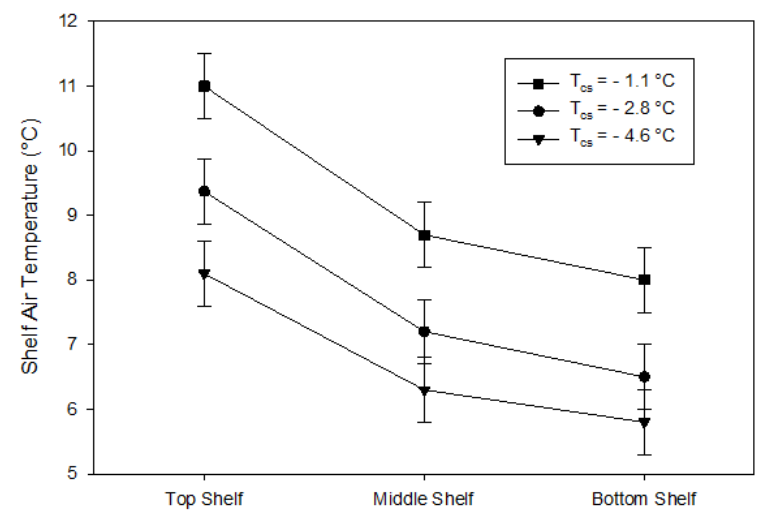

(c)

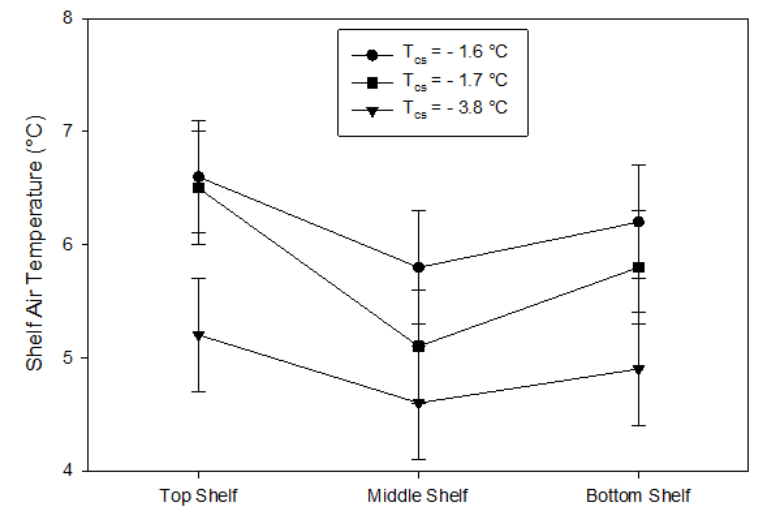

(b)

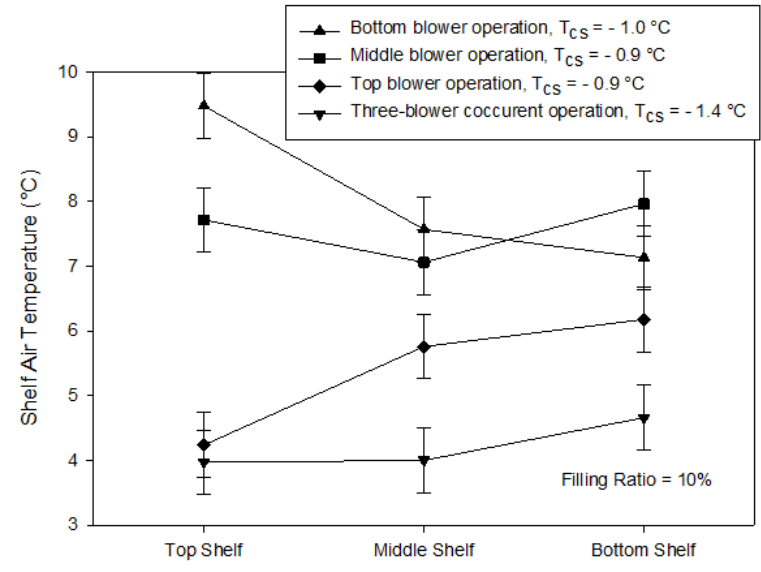

(d)

Fig. 6: Temperature distribution inside the cabinet, (a)-(c) top fan's operation, middle fan's operation, bottom fan's operation, these three operations are at $5 \%$ filling ratio, (d) fan operations at $10 \%$ filling ratio 


\subsection{Thermal Diode Test}

The thermal diode effect, in which the thermosyphon automatically shuts down when the ambient temperature exceeds the interior temperature, was evaluated as follows. All fans in the refrigerator and the climate simulator were turned off, and the refrigerator was provided with AC power so that the OEM cooling system would chill the refrigerated space to $2^{\circ} \mathrm{C}$. The power consumption of the refrigerator was then measured for the climate simulator set at temperatures of $2^{\circ} \mathrm{C}$ and then $28^{\circ} \mathrm{C}$, representing a winter and summer day, respectively. The energy consumption for the $28^{\circ} \mathrm{C}$ simulated hot weather condition was only about $2.5 \mathrm{~W}$ larger than that for the $2^{\circ} \mathrm{C}$ condition. The thermosyphon device is thus conformed to be shutting down once the ambient temperature approaches that of the refrigerated space. The higher energy consumption may result from additional heat leakage due to the fact that the room was about $2^{\circ} \mathrm{C}$ warmer when the $28^{\circ} \mathrm{C}$ case was run.

\subsection{Transient Cooling Test}

Refrigerators must cool food and beverage items to the conditioned temperature after they are initially placed in the refrigerated space. This transient cooling event requires removing the heat in the food in as short of time as possible to maintain freshness [23]. The Japanese Industrial Standard (JIS) test protocol was used for this test, as it is the only known standard to specify transient load test for refrigerators [24]. Eight 500-ml water bottles were used to simulate the food thermal load. The water bottles were initially at room temperature $\left(23 \sim 24^{\circ} \mathrm{C}\right)$, then they were placed in the refrigerated space. A waterproof DS1820 temperature sensor was placed within one bottle to monitor the water temperature as it was cooled. Two test cases were run, as well as a reference case using the OEM refrigeration system. The location, fan configuration, and start/end temperatures for each are shown in Table 3. 
Table 3: Transient test cases

\begin{tabular}{|c|c|c|c|c|c|}
\hline Case & $\begin{array}{c}\text { Water } \\
\text { Location }\end{array}$ & Thermosyphon Fan Use & $\begin{array}{c}\text { Water Start } \\
\text { Temperature } \\
\left({ }^{\circ} \mathrm{C}\right)\end{array}$ & $\begin{array}{c}\text { Water End } \\
\text { Temperature } \\
\left({ }^{\circ} \mathrm{C}\right)\end{array}$ & $\begin{array}{c}\text { Climate } \\
\text { Simulator } \\
\text { Temperature }\left({ }^{\circ} \mathrm{C}\right)\end{array}$ \\
\hline Case 1 & $\begin{array}{c}\text { Middle } \\
\text { Shelf }\end{array}$ & Top fan only & 24.3 & 3.7 & -2.2 \\
\hline Case 2 & $\begin{array}{c}\text { Top } \\
\text { Shelf }\end{array}$ & Top and middle fans & 23.9 & 2.0 & -4.0 \\
\hline Reference & $\begin{array}{c}\text { Middle } \\
\text { Shelf }\end{array}$ & $\begin{array}{c}\text { N/A } \\
\text { (OEM refrigeration used) }\end{array}$ & 23.0 & 2.9 & N/A \\
\hline
\end{tabular}

The results are shown in Fig. 7. As can be seen, for both cases, the thermosyphonassisted cooling system cooled the water more rapidly than the OEM refrigeration system. The total heat removal from water can be determined by

$$
Q=\sum_{i=1}^{N}\left(m C_{p} \Delta T_{i}\right)
$$

where $m=4 \mathrm{~kg}$ is the mass of water in the eight $500 \mathrm{~mL}$ bottles, $C_{p}=4180 \mathrm{~J} \mathrm{~kg}^{-1} \mathrm{~K}^{-1}$ is the specific heat of water, and $\Delta T_{i}$ is the decrease of the water temperature in the $\mathrm{i}^{\text {th }}$ measurement interval. Eq. (5) is plotted in Fig. 8. The accumulated heat removal increased rapidly shortly after the thermal load is placed in the refrigerator load. The thermosyphon cooling system removed heat from thermal load more rapidly than refrigerator OEM cooling system in the same amount of time, Near the end of the measurement for Case 1 at $\sim 500$ min the water temperature increased nominally due to a slight increase in temperature inside the climate simulator. 


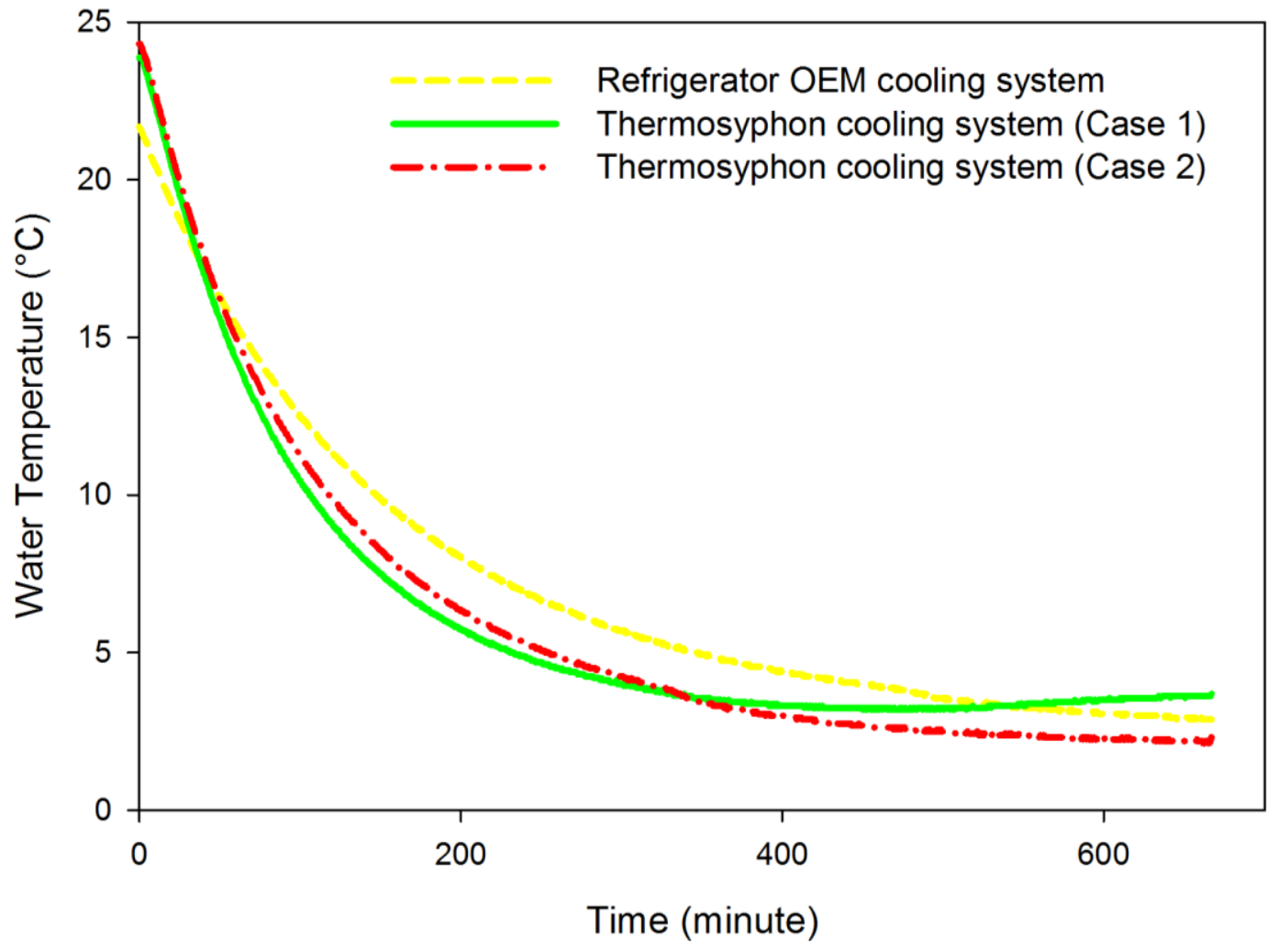

Fig. 7: Dynamic cooling test: (a) Case 1: thermal load on the middle shelf, top and middle fans on, $T_{c s}=-2.2^{\circ} \mathrm{C}$ (b) Case 2: load on the top shelf, top fan on only, $T_{c s}=-4.0^{\circ} \mathrm{C}$.

The yellow dashed line is the reference case using the OEM refrigeration. 


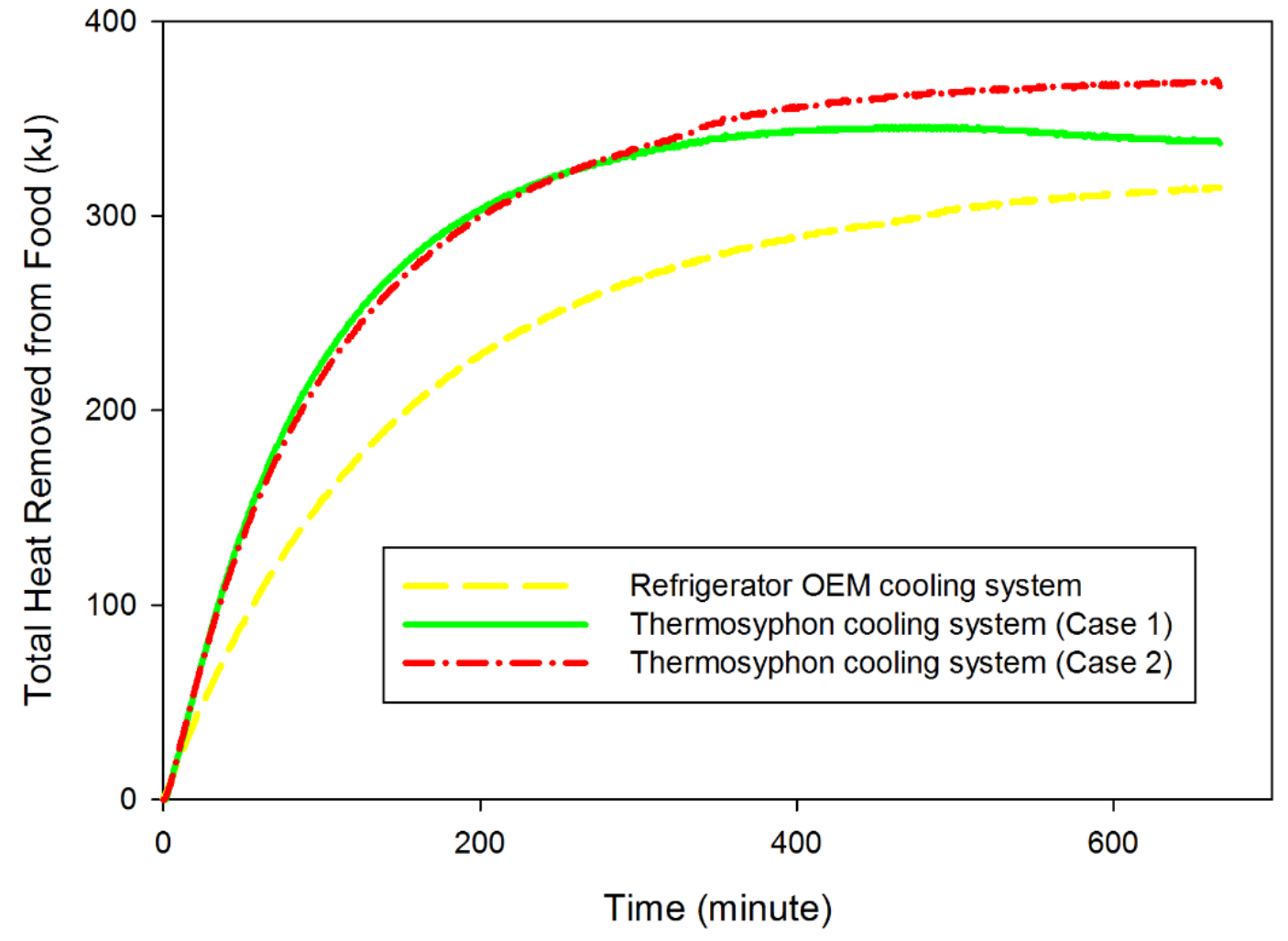

Fig. 8: Total heat removed from food: (a) Case 1: thermal load on the middle shelf, top and middle fans on, $T_{c s}=-2.2{ }^{\circ} \mathrm{C}$ (b) Case 2: load on the top shelf, top fan on only, $T_{c s}=-4.0{ }^{\circ} \mathrm{C}$. Yellow line is the reference case using the OEM refrigeration.

\subsection{Power Consumption, Cost and Further Opportunities for Optimization}

Almost the entirety of the thermosyphon-assisted cooling system's electrical usage is from the fans in the refrigerated space and climate simulator (six total), with a negligible amount of power used to run the microcontroller $(250 \mathrm{~mW})$. The power for each fan was measured and is summarized in Table 4. The measurement error for each fan is $\pm 0.04 \mathrm{~W}$.

Table 4: Power usage by fans 


\begin{tabular}{|c|c|c|c|}
\hline Device & & Fan & Power \\
\hline Climate simulator & gether & All three fans to- & $13.7 \mathrm{~W}$ \\
\hline \multirow{4}{*}{$\begin{array}{l}\text { Refrigerator } \\
\text { Cabinet }\end{array}$} & & Top Fan Power & $4.5 \mathrm{~W}$ \\
\hline & & Middle Fan Power & $4.5 \mathrm{~W}$ \\
\hline & & Bottom Fan Power & $4.2 \mathrm{~W}$ \\
\hline & & Total power & $26.9 \mathrm{~W}$ \\
\hline
\end{tabular}

The total power use when all three fans are on is about $27 \mathrm{~W}$, which is comparable to the power used by the OEM refrigeration system at steady-state conditions. This value can be further reduced if it is possible to shut off one or more fans, depending on the outside conditions.

Table 5 presents cost and savings analysis for several representative cities in the U.S. Typical metrological year (TMY) data [25] is used to determine the number of hours per year when the outside temperature is less than $4.4{ }^{\circ} \mathrm{C}$, and it is assumed that the thermosyphon system will carry the refrigeration load completely in this case. Only the top fan is used in this case, which represents the maximum potential energy savings of the current system. The regional current (2016) electricity rate is used for each city.

Table 5: Estimated Energy Savings by Location in U.S.

\begin{tabular}{|cccccc|}
\hline City & $\begin{array}{c}\text { Electricity Cost } \\
\text { US\$ } / \mathbf{k W h r}\end{array}$ & $\begin{array}{c}\text { Thermosyphon } \\
\text { system annual } \\
\text { usage }\end{array}$ & $\begin{array}{c}\text { Total energy saving } \\
\text { (kWhr) }\end{array}$ & $\begin{array}{c}\text { Annual bill saving } \\
\text { (US\$) }\end{array}$ & $\begin{array}{c}\text { 20-Year bill saving } \\
\text { (US\$) }\end{array}$ \\
\hline New York, NY & 0.177 & $6 \%$ & 24.9 & 4.40 & 88 \\
\hline Washington, D.C. & 0.137 & $8 \%$ & 32.9 & 4.50 & 90 \\
\hline Philadelphia, PA & 0.145 & $8 \%$ & 33.8 & 4.90 & 98 \\
\hline Boston, MA & 0.192 & $10 \%$ & 40.2 & 7.70 & 154 \\
\hline Columbus, OH & 0.130 & $13 \%$ & 51.7 & 6.70 & 134 \\
\hline Denver, CO & 0.117 & $13 \%$ & 52.2 & 6.10 & 122 \\
\hline Ann Arbor, MI & 0.154 & $14 \%$ & 55.8 & 8.60 & 172 \\
\hline Chicago, IL & 0.132 & $16 \%$ & 63.4 & 8.40 & 168 \\
\hline Des Moines, IA & 0.130 & $18 \%$ & 70.6 & 9.20 & 184 \\
\hline Minneapolis, MN & 0.131 & $25 \%$ & 100.1 & 13.10 & 262 \\
\hline
\end{tabular}

Assumes electricity price remains fixed for entire period. 
There are several opportunities to improve the performance of the current system. These include:

- Incorporate high-efficiency PWM fans. The tangential fans were used in this work for their small size and outlet duct geometry that allowed easy coupling to the thermosyphon fins. For optimal energy savings, other fan geometries may provide similar airflow at reduced energy consumption. In particular, low-voltage DC square, axial "muffin" fans are inexpensive, efficient, come in a variety of form factors, and can be driven directly by solar panels.

- Remove thermal contribution from fan heating. The power consumed by the fans in the refrigerated space, which can be up to $13.2 \mathrm{~W}$, is converted to heat that must be removed from the refrigerated space. At steady state conditions, this power can represent an additional $30 \%$ thermal load, beyond the $42.2 \mathrm{~W}$ of normal leakage current. Arranging the fan motors to reside outside of the refrigerated space would remove this thermal burden from the system. The fan mounting would be more complicated, as the fan motor shaft would be required to penetrate the refrigerated space envelop, however the energy savings would be significant.

- Eliminate condenser fans. It may be possible to eliminate the condenser fans completely. Space is much less of an issue outside of the house envelope, hence considerably larger fins can be used, as well as a longer condenser section. The fin design can also factor in local average wind speeds. It may thus be possible to design the condenser heat exchanger so that no fans are required. If fans are necessary, it may be possible to shut them down when the wind speed is sufficient to provide additional energy savings.

- Optimize the fin structure on the thermosyphons. The current fin type and spacing were restricted by the availability of a tubing manufacturer to provide. An optimized fin configuration in terms of fin spacing, fin length, shape (simple, louvered, etc.) would maximize heat 
transfer with minimal airflow and pressure drops, which would also reduce the required fan power [26-28].

\section{Micro-Climate CONCEPT}

As shown in Fig. 7, the temperature in the refrigerated space can vary substantially with the thermosyphon-assisted cooling system, depending on which fans are on. This can be used as an advantage to save additional electricity by implementing a micro climate in the refrigerated space. The idea is to have only a portion of the refrigerator maintained at or below the target of $4.4{ }^{\circ} \mathrm{C}$ or less for perishable foods, while other regions of the refrigerator can be run warmer for foods and beverages that favor slightly higher temperatures and/or are not susceptible to spoilage. Examples of the latter include canned and non-dairy beverages, water, condiments, bread, fruits, and vegetables [29]. In contrast, a traditional refrigerator cooling system cools the entire space to the same temperature. The refrigeration system's OEM cooling system can be used to ensure the cold-temperature regions of the refrigerator are not exceeded.

In addition, the results in Fig. 5 and Fig. 6 suggest that the optimal configuration for a micro-climate configuration would be to run the top fan only, with the top shelf serving as the coldest portion of the refrigerator. Temperature sensors placed on each shelf can be used to drive the corresponding fan for that shelf. The shelves could be thermally insulated, and color-coded, e.g., blue, green, red for cold, chilled, and cool shelves, respectively, for easy recognition. The user could have the option of adjusting each shelf temperature as desired, and the microcontroller could also report total energy usage and temperature history as feedback to maximize energy savings. In commercial refrigeration examples, food items can be separated by their required storage temperature to ensure that spoilage or cross contamination does not occur. 
Another very important consequence of allowing warmer refrigeration temperatures is that the proposed refrigeration concepts can be used in significantly warmer climates and/or for more hours per year. As discussed earlier, the coldest achievable refrigeration temperature is directly related to the outside temperature. By allowing the refrigeration temperature to rise, the warmer portions of the refrigerator can use thermosyphon cooling for a larger number of hours per year.

\section{CONCLUSIONS}

This article presents a thermosyphon-based cooling system for residential and commercial refrigeration systems. The system uses cold outside temperatures to provide low-cost cooling for energy savings. Tests were performed on a residential refrigerator and a thermosyphon made from a finned copper tube. Outdoor conditions were simulated with a cooled air space above the refrigerator. It was found that the refrigerated space can be maintained within $\sim 5^{\circ} \mathrm{C}$ of the outside ambient temperature for a range outside temperatures. The impact of the outdoor air temperature and the fans were investigated. Temperatures below the maximum recommended temperature of $4.4^{\circ} \mathrm{C}$ were achieved with outside temperatures as high as $-0.8^{\circ} \mathrm{C}$. Using fewer fans increases some regions of the refrigerated space temperature. A micro-climate concept is proposed in which only a portion of the refrigerator is cooled below the $4.4^{\circ} \mathrm{C}$ target, while the balance of the refrigerator runs slightly warmer.

Opportunities for further work include optimizing the fan and fin configuration to minimize the fan electricity consumption, moving the fan motors outside of the refrigerated space to eliminate their thermal load, and incorporating thermal energy storage to capitalize on lower temperatures at night. Another concept is to use the thermosyphons to cool the condensers on a 
normally operating refrigeration system. By reducing the average condenser temperature, the overall COP will increase. Furthermore, since the condenser temperature is typically well above the ambient room temperature, this would allow the system to be used for a larger fraction of the year in many regions of the country.

\section{ACKNOWLEDGMENTS}

This work was supported by the U.S. Department of Energy and Lawrence Berkeley National Laboratory 2012/2013 Max Tech and Beyond Program.

\section{REFERENCES}

1. U.S. Energy Information Administration, Annual energy outlook 2015, Data table A4. 2015.

2. U.S. Energy Information Administration, COMMERCIAL BUILDINGS ENERGY CONSUMPTION SURVEY (CBECS), . 2016.

3. Dunn, P.D. and D. Reay, Heat pipes. 2012: Elsevier.

4. Faghri, A., Heat pipe science and technology. 1995: Global Digital Press.

5. U.S. Environmental Protection Agency and U.S. Department of Energy ENERGY STAR® [cited 2016, May 12]; Available from: www.energystar.gov.

6. Jouhara, H. and H. Merchant, Experimental investigation of a thermosyphon based heat exchanger used in energy efficient air handling units. Energy, 2012. 39(1): p. 82-89.

7. Lukitobudi, A.R., et al., Design, construction and testing of a thermosyphon heat exchanger for medium temperature heat recovery in bakeries. Heat Recovery Systems and CHP, 1995. 15(5): p. 481-491.

8. Zhi, W., et al., Analysis on effect of permafrost protection by two-phase closed thermosyphon and insulation jointly in permafrost regions. Cold Regions Science and Technology, 2005. 43(3): p. 150-163.

9. Esen, M. and H. Esen, Experimental investigation of a two-phase closed thermosyphon solar water heater. Solar Energy, 2005. 79(5): p. 459-468.

10. Chow, T.T., W. He, and J. Ji, Hybrid photovoltaic-thermosyphon water heating system for residential application. Solar Energy, 2006. 80(3): p. 298-306.

11. SunFrost. Cold weather passive assist refrigeration. [cited 2016, May, 12]; Available from: http://www.sunfrost.com/passive_refrig.html. 
12. Cold Climate Housing Research Center, Passive Refrigeration. 2013.

13. Dunn, P.D. and D. Reay, Heat pipes. 1982: Elsevier.

14. El-Genk, M. and H. Saber, Heat transfer correlations for liquid film in the evaporator of enclosed, gravity-assisted thermosyphons. Journal of heat transfer, 1998. 120(2): p. 477484.

15. El-Genk, M.S. and H.H. Saber, Heat transfer correlations for small, uniformly heated liquid pools. International journal of heat and mass transfer, 1998. 41(2): p. 261-274.

16. El-Genk, M.S. and H.H. Saber, Determination of operation envelopes for closed, twophase thermosyphons. International journal of heat and mass transfer, 1999. 42(5): p. 889-903.

17. Dobran, F., Steady-state characteristics and stability thresholds of a closed two-phase thermosyphon. International Journal of Heat and Mass Transfer, 1985. 28(5): p. 949-957.

18. Nguyen-Chi, H. and M. Groll, Entrainment or flooding limit in a closed two-phase thermosyphon. Journal of Heat Recovery Systems, 1981. 1(4): p. 275-286.

19. Jiao, B., et al., Investigation on the effect of filling ratio on the steady-state heat transfer performance of a vertical two-phase closed thermosyphon. Applied Thermal Engineering, 2008. 28(11): p. 1417-1426.

20. ESDU (Engineering Sciences Data Unit), Heat Pipes - performance of two-phase closed thermosyphons. (No. 81038C),. 1983.

21. Shiraishi, M., K. Kikuchi, and T. Yamanishi, Investigation of heat transfer characteristics of a two-phase closed thermosyphon. Journal of Heat Recovery Systems, 1981. 1(4): p. 287-297.

22. U.S. Food and Drug Administration. Refrigerator Thermometers: Cold Facts about Food Safety,. [cited 2016, May 12]; Available from: http://www.fda.gov/Food/ResourcesForYou/Consumers/ucm253954.htm.

23. Fukuyo, K., T. Tanaami, and H. Ashida, Thermal uniformity and rapid cooling inside refrigerators. International Journal of Refrigeration, 2003. 26(2): p. 249-255.

24. Geppert, J., Modelling of domestic refrigerators' energy consumption under real life conditions in Europe. 2011.

25. NREL. National Renewable Energy Laboratory - TMY Data. Available from: http://rredc.nrel.gov/solar/old_data/nsrdb/1991-2005/tmy3/.

26. Shah, R.K. and D.P. Sekulic, Fundamentals of heat exchanger design. 2003: John Wiley \& Sons.

27. Rohsenow, W.M., J.P. Hartnett, and Y.I. Cho, Handbook of heat transfer. Vol. 3. 1998: McGraw-Hill New York.

28. Webb, R.L. and N.-H. Kim, Principl of enhanced heat transfer. Taylor Francis: New York, NY, USA, 1994. 
29. European Food Information Council. Proper Food Storage in the Refrigerator. 2001 07/09/2014]; Available from: http://www.eufic.org/article/en/food-safety-quality/safefood-handling/artid/food-storage-refrigerator/. 